Volume: 7

Issue: 2

Month: March

Year: 2019

ISSN: 2319-961X

Received: 4.3.2019

Accepted: 9.3.2019

Published: 15.3.2019

Citation:

Sangamithra, A., and P. Arunkumar. "A Study on the Determinants of Expenditure Incurred for Agricultural Workers for Illness Related to Health Hazards in Theni District, Tamil Nadu."

Shanlax International Journal of Economics, vol. 7, no. 2, 2019, pp. 27-33.

DOI:

https://doi.org/10.34293/ economics.v7i2.312

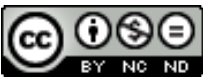

This work is licensed under a Creative Commons AttributionNonCommercialNoDerivatives 4.0 International License

\section{A Study on the Determinants of Expenditure Incurred for Agricultural Workers for Illness Related to Health Hazards in Theni District, Tamil Nadu}

A.Sangamithra

Professor, Department of Economics

Bharathiar University, Coimbatore, Tamil Nadu, India

\section{P.Arunkumar}

Department of Economics

Bharathiar University, Coimbatore, Tamil Nadu, India

\begin{abstract}
Agricultural work all over the world is hazardous, resulting in a large number of injuries to farmers or even death. According to the International Labor Organization (ILO), the agricultural sector is one of the most hazardous to health worldwide (ILO, 2000). Olatunji et al. (2013) pointed out that the productivity of farmers is affected by some occupational hazards and health problems such as Malaria, musculoskeletal disorders, farm injuries, yellow fever, Diarrhoea diseases, respiratory diseases and skin disorder (Olatunji SO, 2013). They usually get low wages, conditions of work put an excessive burden on them, and the employment which they irregular. Their income is low, and employment is unequal. Since they possess no skill or training; they have no alternative job opportunities either. Health system in our country is bogged down with some of chronic maladies like inappropriate budgetary allocation and a "top-down" hierarchy with multiple levels of operation which have led to compromise in effectiveness and quality of the services. Out of pocket expenditure becomes a burden for the poor especially when they have to spend vast amounts from their disposable income. The financial burden borne by people with healthcare and their families as a result of their disease depends on their economic status. In the poorest countries, people with health and their families bear almost the whole cost of the medical care they can afford. Besides excess healthcare expenditure, chronic diseases impose great economic burdens in the form of loss of productivity and foregone economic growth.
\end{abstract}

Keywords: Health, Healthcare, Financial Burden, Expenditure, Hazards, Injuries, Quality, Diseases, Out of pocket, Medical Care

\section{Introduction}

One of the most distinguishing features of the rural economy of India has been the growth in the number of agricultural workers, cultivators and agricultural laborers engaged in crop production. The phenomena of underemployment, under-development and surplus population are simultaneously manifested in the daily lives and living of the agricultural laborers. They usually get low wages, conditions of work put an excessive burden on them, and the employment which they get is extremely irregular. Agricultural workers constitute the most neglected class in Indian rural structure. Their income is very low, and irregular employment. Since they possess no skill or training, they have no alternative employment opportunities either. Socially, a large number of agricultural workers belong to scheduled castes and scheduled tribes. 
Therefore, they are a suppressed class. They are not organized, and they cannot fight for their rights. Because of all these reasons, their economic lot has failed to improve even after all these years of planning. In most countries, only some categories of agricultural workers are covered by national legislation, employment injury benefits or insurance schemes. A large number of agricultural workers are thus deprived of any form of social protection. When national regulations exist, they are often sporadically applied. Effective enforcement is poor due to insufficient labor inspection, lack of understanding and training on hazards and their prevention of both of employers and workers and low levels of organization among agricultural workers (Vetrivel et al., 2013). It is clear that Agricultural work all over the world is hazardous, resulting in a large number of injuries to farmers or even death. According to the International Labor Organization (ILO), the agricultural sector is one of the most hazardous to health worldwide (ILO, 2000). Olatunji et al. (2013) pointed out that the productivity of farmers is affected by some occupational hazards and health problems such as Malaria, musculoskeletal disorders, farm injuries, yellow fever, Diarrhoea diseases, respiratory diseases and skin disorder (Olatunji SO, 2013). Other literature explained the effects of some hazards on farming activities: Exposure to dust, fumes gases and particulates, snake and insect, weather and climate, carrying and lifting loads, poor farming posture and hazard due to farm tools (Donald C, 2006). Some of the reason is that farmers do not put on the necessary protective clothing when using chemicals and necessary equipment is not used (Onasanya AS, 2006). The health status of farmers determines the output of his/her labor supply and hence agricultural productivity. Egbetokun et al. opine that there is a correlation between health and productivity of labor (Egbetokun OA, 2012). Illhealth arising from agricultural work has negative implications for agricultural productivity.

\section{Objective of the study}

- To study the expenditure incurred for treatment and Source of Finance among agricultural workers.

\section{Data and Methods}

An attempt was made in this research to analyze the expenditure incurred for treatment of agricultural workers in Theni district. Totally five taluks have been conducted, namely Andipatti, Bodinayakanur, Periyakulam, Theni, and Uthamaplayam coming under Theni district among 500 agriculture workers from different taluks.

\section{Area of the Study}

Theni District situated in between latitude 9030 and 10030 and longitude 77000 and 78030 with an area of $3242.30 \mathrm{sq} . \mathrm{km}$. It is an inland district. It is encompassed on the West by Kerala State, on the East by Madurai District, on the North by Dindigul District and the South partly by Kerala State and partly by Virudhunagar District. Agriculture is the primary occupation of the district, and 67 percent of its population lives in rural areas. Theni enjoys the salubrious climate. Its maximum temperature is $38.50 \mathrm{C}$, and the minimum is $26.30 \mathrm{C}$. The climate is conducive for Agricultural and Horticultural crops. In Theni district, the pesticides residues and fertilizers from the agricultural fields in, and around the area of Theni district contaminate many rivers including Mullaiperiyar River. The river water is slowly polluting because of the above activities on the river bank. Due to pollution of Mullaiperiyar River water, the groundwater in and around the river are also affected. In Future, the groundwater will be completely polluted if a prevention measure is not taken and due to heavy use of pesticides, agricultural workers in Theni district is also affected by various diseases. The agriculture workers of this area are prone to unhealthy working conditions (Ramakrishnan D et al., 2012).

\section{Healthcare Cost payment by the respondents}

Health system in our country is bogged down with some chronic maladies like inappropriate budgetary allocation and a "top-down" hierarchy with multiple levels of operation which have led to compromise in effectiveness and quality of the services. Although, in the last few decades considerable progress has definitely is made for expansion of the public health infrastructure, the mere existence or increasing the availability of services does not increase 
their utilization. Health care covers not merely medical care but also all aspects of pro preventive care too. Nor can it be limited to care rendered by or financed out of public expenditure within the government sector alone but must include incentives and disincentives for self-care and care paid for by private citizens to get over ill health. Where, as in India, private out-of-pocket expenditure dominates the cost financing health care, the effects are bound to be regressive. Heath care at its essential core is widely recognized to be a public good. Its demand and supply cannot, therefore be left to be regulated solely by the invisible of the market. Nor can it be established on considerations of utility maximizing conduct alone. Household health expenditures are the expenditures incurred by households on health care and include out of pocket expenditures and prepayments. Out of pocket expenditure are the payments made directly by individuals at the point of service where the entire cost of the health good or service is not covered under any financial protection scheme. When an individual/household has to bear the expenditures for health care out of pocket, most of the times expenditures tend to be high about their income thereby leading to low living standards (reduction in expenditure on necessities like food and clothing). Out of pocket expenditure becomes a burden for the poor especially when they have to spend huge amounts from their disposable income.

Table 1: Healthcare Cost Payment

\begin{tabular}{|l|c|c|}
\hline \multicolumn{1}{|c|}{ Payment } & Frequency & \% \\
\hline $\begin{array}{l}\text { Not taken/ } \\
\text { required }\end{array}$ & 10 & 2.0 \\
\hline Taken free & 23 & 4.6 \\
\hline Partly free & 122 & 24.4 \\
\hline $\begin{array}{l}\text { Fully paid by } \\
\text { the patient }\end{array}$ & 345 & 69.0 \\
\hline \multicolumn{1}{|c|}{ Total } & $\mathbf{5 0 0}$ & $\mathbf{1 0 0 . 0}$ \\
\hline
\end{tabular}

Source: Primary data

The above Table explains healthcare cost payment made by the sample respondents for taking treatment. Out of the 500 sample respondents 345 (69 percent) paid the full amount for treatment, 122 (24.4 percent) respondents paid partly, 23 (4.6 percent) respondents took free treatment and only 10
(2 percent) respondents did not take any treatment in any healthcare sector.

\section{Expenditures for Treatment of the Respondents}

The Table below depicts the burden of health diseases showing the total of both direct and indirect costs. The table below shows the total of both direct and indirect cost of the sample respondents viz. Admission fee, doctor fee, medicine, diagnostic surgery, ICU and room rent, will come under the direct cost. Transport charges and food expenses will come under indirect cost. The details are given below.

Table 2: Expenditures for Treatment

\begin{tabular}{|l|c|c|}
\hline $\begin{array}{c}\text { Total Expenditures } \\
\text { (in. Rs.) }\end{array}$ & Frequency & \% \\
\hline No Expenditure & 33 & 6.6 \\
\hline 3000 or less & 228 & 45.6 \\
\hline $3001-6000$ & 61 & 12.2 \\
\hline 6001 \& above & 178 & 35.6 \\
\hline Total & $\mathbf{5 0 0}$ & $\mathbf{1 0 0 . 0}$ \\
\hline
\end{tabular}

Source: Primary data

The above Table shows that, out of the total of 500 sample respondents, 467 workers incurred the expenditure for their hospitalization. A majority of 228 workers (45.6 percent) paid an amount of Rs.3000 and below, 178 workers (35.6 percent) paid above Rs.6,000, 61 workers (12.2 percent) paid between Rs.3,000-6,000 and 33 workers (6.6 percent) did not incur any medical expenses during hospitalization for the last one year period.

\section{Source of finance}

Income level or purchasing power has a direct effect on the potential demand for the product or service. People coming from each income group may have comparable incomes, but their sources of income and usage pattern may be relatively different. Thus, the income levels of the people are influenced by the sources of income and these together will affect the utilization of healthcare services. There is direct co-relationship between higher income and demand for quality products and services and capital - an intensive healthcare service is not an exception. The important fact is that with rising personal and 
household income, the ability of the people to pay for quality healthcare services also increases considerably. Expenditure statistics may not adequately reveal the full implications of ill-health on long-term standards of living and poverty, if people living at the margins of subsistence end up selling their foremost income-earning assets, or borrowing at usurious rates of interest. The treatments of diseases are expensive and can consume a substantial part of a household's financial resources since the patients require treatment over a long period and require hospitalization sometimes. In countries like India, where healthcare is predominantly financed through out-of-pocket payments, financing treatment of chronic diseases can be particularly burdensome, especially for poorer households. The issue of socioeconomic inequalities in out-of-pocket expenditures and methods of financing treatment of diseases has not received the attention it deserves in India. Hence to accommodate unexpected and high healthcare spending, households reduce the consumption of other goods and services leaving them more vulnerable to impoverishment, forego treatment, borrow money, sell assets, draught animals and others as the source of finance to expenditure treatments.

Table 3: Source of Finance $(N=467)$

\begin{tabular}{|l|c|c|}
\hline \multicolumn{1}{|c|}{ Source of finance } & Frequency & \% \\
\hline Past Savings & 283 & 60.6 \\
\hline $\begin{array}{l}\text { Current } \\
\text { Income }\end{array}$ & 136 & 29.0 \\
\hline Borrowing & 102 & 21.8 \\
\hline Sale of Animals & 56 & 12.0 \\
\hline Government Schemes & 40 & 5.2 \\
\hline Sale of Physical Assets & 14 & 3.0 \\
\hline
\end{tabular}

Source: Primary data

The above Table explains the finance acquired by the respondents from a different source. Around 283 respondents depended on past savings as a source of money, 29 percent of the respondents had used their current income, borrowing from their friends, family members and others were the source of finance for the treatment for 102 respondents (21.8 percent), 12 percent of the respondents got their finance for treatment through selling their Livestock, only 3 percent have sold their physical assets and around 5.2 percent of the respondents' have got benefits from government schemes in order to get the finance for the treatment. Tamilnadu government gave financial assistance to the family for healthcare treatment like Chief Minister's Comprehensive Health Insurance Scheme, Chief Minister's Uzhavar Padhukappu Thittam and central government health schemes like Antyodaya Anna Yojna, Pradhan Mantri Bhartiya Janaushadhi Pariyojana, etc. The concept of government sponsored-health insurance schemes has emerged with the aim of providing financial cover to poor households during catastrophic health shocks. In Tamilnadu, the Chief Minister's Comprehensive Health Insurance Scheme was launched in 2011 to provide "quality medical care for identified specialty services requiring hospitalization for surgeries and medical procedure." The main objective of the scheme is to enable access to healthcare for the lower income sections of the society. The enrolment is limited to families whose annual income is less than Rs.72, 000. This report traces the progress of the Chief Minister's Comprehensive Health Insurance Scheme in Tamilnadu till about mid-2016. The scheme is implemented by the state government through the Project Director, Tamil Nadu health system project. The enables families to derive a maximum benefit or Rs.4 lakh over four years, with an annual limit of Rs.1 lakh, and a provision to get benefit up to Rs.1.5 lakh for certain specified procedures. The benefit is on a floater basis. Most, unfortunately, these do not reach the rural people but are siphoned away by miscreants who are middle men and corrupt officials. It is a pity that these classes of people of our country are not served well at all despite the resolve of the government towards these people.

\section{Multiple Linear Regression Analysis on Total Expenditure for Treatment of Diseases}

For identifying the factors that determine the total cost incurred for treatment of diseases the multiple linear regression analysis is carried out, and the results are presented in Table 4. 
Table 4: Results of Multiple Linear Regression Analysis on Total Expenditure for Treatment of Diseases

\begin{tabular}{|l|c|c|c|}
\hline \multicolumn{1}{|c|}{$\begin{array}{c}\text { Explanatory } \\
\text { Variables }\end{array}$} & $\begin{array}{c}\text { Standardized } \\
\text { Coefficient (B) }\end{array}$ & t-value & p-value \\
\hline Age (in Years) & 0.253 & 5.086 & 0.001 \\
\hline $\begin{array}{l}\text { Size of the } \\
\text { Family (Members) }\end{array}$ & -0.097 & 2.027 & 0.05 \\
\hline $\begin{array}{l}\text { Education (in Six } \\
\text { levels) }\end{array}$ & -0.067 & 1.481 & 0.130 \\
\hline $\begin{array}{l}\text { Average Monthly } \\
\text { Individual } \\
\text { Income (in Rs.) }\end{array}$ & -0.243 & 3.061 & 0.001 \\
\hline $\begin{array}{l}\text { Average Monthly } \\
\text { Family Income } \\
\text { (in Rs.) }\end{array}$ & -0.530 & 8.080 & 0.001 \\
\hline $\begin{array}{l}\text { Total Monthly } \\
\text { Expenditure (in } \\
\text { Rs.) }\end{array}$ & 0.364 & 6.088 & 0.001 \\
\hline $\begin{array}{l}\text { Total Value of } \\
\text { Assets Owned (in } \\
\text { Rs.) }\end{array}$ & 0.133 & 2.667 & 0.01 \\
\hline Sex (Ref: Males) & 0.359 & 5.041 & 0.001 \\
\hline $\begin{array}{l}\text { Social Background } \\
\text { (Ref. SC/ST) } \\
\text { Most Backward \& } \\
\text { Backward Castes }\end{array}$ & 0.088 & 2.218 & 0.05 \\
\hline $\begin{array}{l}\text { R2 (in \%) } \\
\text { Total Sample }\end{array}$ & & $\mathbf{5 0 0}$ & \\
\hline
\end{tabular}

\section{Determinants of Total Expenditure Incurred for Treatment of Diseases}

In the preceding section, gross differentials in the total cost incurred for treatment of diseases (in categories) are examined through cross-tabular analysis with the Chi-Square test of significance. Such simple tabulations provide an overall understanding of the nature of the relationship between the independent variables (background characteristics of respondents) and the dependent variable (total cost incurred for treatment of diseases) on one to one basis, and therefore, these are less conclusive. But in common phenomena, at a point of time, any dependent variable would not only be influenced by one independent variable but also by several other such variables. Under these circumstances, the multivariate analysis allows us a more accurate assessment of each of the explanatory variable by taking into account the potential confounding effects of other variables used in the model. Such an analysis would help us to know the crucial determinants of the dependent variable under consideration, which would be very useful to suggest policy implications and programmes for looking after the medical and health services related to the treatment of diseases. Keeping this in mind, an attempt is made here to analyze the principal determinants of the total expenditure incurred for the treatment of diseases with the help of a multivariate technique. In the present context, the dependent variable, total expenditure for treatment of diseases treated as a continuous variable in nature (i.e., the actual amount spent in Indian Rupees), and hence, multiple linear regression analysis is felt to be most appropriate. The independent (explanatory) variables considered for analysis are based on the theoretical importance as well as their levels of significance with the dependent variable. However, out of the nine variables included in the model, seven are continuous (or discrete) in nature and the other 2 are dummy variable type. More details about the multiple linear regression analysis are provided in the chapter on Methodology. Results based on multivariable analysis are provided in Table 4.

Data provided in Table 4 reveals that, among the total sample respondents, all the nine variables included in the model together have explained about 29 percent variation in total expenditure incurred for the treatment of diseases. Controlling for all the variables included in the model, the total expenditure spent for treatment of diseases from which respondents suffered appear to be on increasing side significantly with an increase in their total expenditure per month at family level $(\beta=0.363 ; p<0.001)$ as well as with the total value of assets they possess $(\beta=0.133 ; p<0.01)$. These results indicate that, on the one side, the tendency to spend more and money for treatment of diseases obviously on the increasing side may be because of the tendency to cure the diseases at any cost and further, those respondents who are affordable due to their total assets owned. Another 4 expected the direction of positive net effect on the total amount of expenditure incurred on diseases is positive and highly significant $(\beta=0.253 ; \mathrm{p}<0.001)$. On the other side, it is conspicuous to note that the total amount spent for treatment of diseases is significantly higher 
for females than males $(\beta=0.359 ; p<0.001)$ and also among those who belong to the most backward and backward castes, but at a moderate extent of significance $(\beta=0.088 ; p<0.05)$ infertility treatment if they have big rate of assets, since they can bear such cost with less hassle.

Conversely, it is pertinent to note that the total cost incurred for treatment of diseases is appears to be decreasing with an increase in the average monthly family as well as individual income $(\beta=-0.530$ and $-0.243 ; p<0.001$ each, respectively). Such pattern may be because of the reason that only healthy person will be able to work and the person who is sick will be unable to work and earn their income, if they can to work, they will not spend much on treatment were healthy. Further, income earned by family, i.e., when the family earns more they are affordable to spend more in preventing the diseases rather than spending in curing the diseases. Besides, these reasons, as already stated, it is the accepted human tendency to spend higher amounts for treatment of diseases even they earn lower incomes since life is important than money, and thereby, respondents who are in lower economic status even go for borrowing the amounts for treatment from relatives, friends, and neighbors, besides personal or family sources. Another factor, which is negatively related is the households size, which reveals that higher the number of family members lower will be the tendency to spent for treatment of diseases to a moderate extent $(\beta=-0.097$; $\mathrm{p}<0.05$ ). Lastly, the remaining variable, educational status though showed an expected negative effect on the total amount spend on the disease, the t-test results did not turn out as significant.

In sum, the multiple regression analysis results on the total expenditure incurred for treatment of diseases highlight that the such cost has increased significantly (at different levels) with an increase in the sample women's current age, total monthly family expenditure and total value of assets owned by the respondents, whereas such cost is also found to be higher for those women as against men and for those belonging to the most backward and backward castes than their SC/ST counterparts. On the opposite side, the role of average monthly family and individual income as well as the size of the household, tend to have a depressing (negative) effect on the expenditure spent for treatment of diseases. Respondents' educational level has exhibited a little bit negative net effect on the total cost for treatment but in a significant way.

\section{Conclusion}

The financial burden borne by people with healthcare and their families as a result of their disease depends on their economic status. In the poorest countries, people with health and their families bear almost the whole cost of the medical care they can afford. Besides excess healthcare expenditure, chronic diseases impose large economic burdens in the form of loss of productivity and foregone economic growth. Patients not only spend their money, but also the time and energy were invested. The main findings of the present chapter are as follows.

- $\quad$ Around 69 percent of respondents have paid the full amount for taking treatment.

- When the researcher calculated the direct and indirect cost for treatment, for 6.6 percent respondents there is no expenditure incurred. However, 45.6 percent of respondents have spent Rs. Three thousand or below and 35.6 percent have spent Rs.6,001 and above for taking treatment.

- When the researcher asked questions about the source of finance, it was found that most of the sample agricultural workers (60.6 percent) spent money from past savings followed by 29 percent who have spent from their current income for taking treatment.

For identifying the factors that determine the total cost incurred for treatment of diseases, the multiple linear regression analysis was carried out and results shows that the treatment cost has increased significantly (at different levels) with an increase in the sample women's current age, total monthly family expenditure and total value of assets owned by the respondents, whereas such cost is also found to be higher for those women as against men and for those who belong to the most backward and backward castes than their $\mathrm{SC} /$ ST counterparts. On the opposite side, the role of average monthly family and individual income, as well as the size of the household, tends to have a 
depressing (negative) effect on the expenditure spent on treatment of diseases. Respondents' educational level has exhibited a little bit negative net effect on the total cost for treatment but in a significant way. The study, therefore, recommends the need for the government and relevant agencies to encourage farmers by providing them protective equipment at subsidized cost through extension agents who will train farmers on their use. Also, there is a need for a public health agency to educate farmers on personal healthcare practices and the need to consult medical personnel as soon as possible in case of any form of occupational hazard.

\section{References}

International Labor Organisation (ILO), 2000.

Safety and health, in agriculture. International Labor Conference, 88th Session, Geneva, 2000. Report VI (1). Geneva, pp: 108. ISBN 92-2-111517-8, SFR15.

Olatunji SO, Ehebha EO \& Ifeanyi-Obi CC "Utilization of western and traditional healthcare services by farm families in Ukwa-
East Local Government Area of Abia State," Nigeria. J Agr Soc Res 13 (2): 111-120. 2013. Ramakrishnan, D., Dheenadayalan, M. S., \& Sivakumar, K. K. "Journal of Chemical, Biological and Physical Sciences Environmental Impact Studies of Mullaiperiyar River Water in Theni District on Ground Water," 2(4), 2123-2128, 2012.

Vetrivel, V \& Manigandan, R., "An empirical study of agricultural labor in India." J. Exclusive Management Sci., Vol.2 no.12, ISSN 22775684,2013

\section{Websites}

http://www.slideshare.net/ramnikparekh/ agriculture-iaoh-bohs.

https://sol.du.ac.in/mod/book/view. php?id $=1735 \&$ chapterid $=1697$.

https://wenku.baidu.com/ view/5cac0863581b6bd97f19eab4.html

http://shodhganga.inflibnet.ac.in/ bitstream/10603/30157/2/chapter\%201.pdf

\section{Author Details}

Dr.A.Sangamithra, Professor, Department of Economics, Bharathiar University, Coimbatore, Tamil Nadu, India Email ID: sangamithra@buc.edu.in

Dr.P.Arunkumar, Department of Economics, Bharathiar University, Coimbatore, Tamil Nadu, India

Email ID: aruncinna89@gmail.com 